\title{
JULIO C. TELLO, 25 AÑOS DESPUÉS
}

\author{
Luis Guillermo Lumbreras
}

En 1957 cuando se cumplieron los diez primeros años de la muerte del Dr. Julio C. Tello, el Centro de Estudiantes de Antropología, que acabábamos de fundar, organizó en esta misma Aula Magna de la Facultad de Letras, un homenaje al sabio; se me encargó, entonces, como Presidente del Centro, hacer un balance de lo que había ocurrido en aquellos 10 años. Ahora, transcurridos quince años más, me toca nuevamente, en suerte, el rendir el balance de estos veinticinco años, como homenaje de la Universidad al desaparecido maestro y del Museo de Arqueología a su fundador. No es, pues, casual, que divida en dos mi exposición: en la primera parte me ocuparé de los diez primeros y en la segunda de los quince últimos años. Quiero decir también, que esta división no responde únicamente al azar, sino que representa, al mismo tiempo, una significación separación en el proceso de la arqueología peruana. Sobre algo de esto hablamos ya en la inauguración del I Congreso Peruano de Arqueología Andina, en enero último y no lo vamos a repetir.

\section{A. LA obra De Tello}

Para establecer el balance, es menester recordar brevemente la obra del Dr. Tello y su significado.
Cuando Tello comenzó a hacer Arqueología, nadie en el Perú la había hecho antes y sólo el alemán Dr. Max Uhle había iniciado la investigación del país en ese rubro. Esto había iniciado la investigación del país por los monumentos antiguos y la historia de los antiguos peruanos; en realidad esa preocupación existió a lo largo de los siglos de dependencia colonial y semi-colonial, con los cronistas, viajeros, historiadores y coleccionistas de antigüedades. Pero todo esto visto desde el exterior con algunas excepciones y en forma no sistemática. Con Tello se inició una arqueología científica hecha por peruanos. Esto parecería una vulgar postura chauvinista si no fuera que pasamos a analizar.

Tello no aparece, en el problema de la ciencia histórica, como una entidad aislada; su figura se liga a una etapa que cronológicamente puede ser precisada entre 1919 y 1939, aun cuando él y sus contemporáneos hubieron logrado vigencia durante muchos años más, como en efecto sucedió con el Dr. Tello que vivió ocho años más, hasta 1947.

Entre 1919 y 1939 se gestó la ciencia social en el Perú, paralelamente a la participación del pueblo en la lucha social, paralelamente a la construcción de las grandes líneas teóricas sobre el proceso peruano. En la primera parte de este periodo (1919-29), junto con Tello, sur- 
gieron Luis E. Valcárcel, José Carlos Mariátegui, Víctor Raúl Haya, Luis Alberto Sánchez, Ricardo Martínez de la Torre y luego Jorge Basadre, Raúl Porras Barrenechea, etc. En la etapa en la que la movilización popular engendró una teoría popular. A nivel de lucha de clases, el campesinado era la fuerza más importante del proceso, enfrentando a los terratenientes, que constituían una oligarquía de extracción foránea; el proletariado urbano recién se dejaba sentir gracias a la lucha por la jornada de las 8 horas que se iniciaron pocos años atrás y la pequeña burguesía estaba obligada a los terratenientes o ligeramente emergente en las ciudades, sin más fuerza que la que le permitió tener la movilización obrera durante el periodo en que se gestó la llamada Reforma Universitaria, de donde precisamente surgieron las personalidades que acabamos de mencionar y otras que no anotamos a favor de la extensión de este discurso.

Consecuentemente, la contradicción principal en el seno de la sociedad peruana residía en la lucha entre campesinos y terratenientes; los campesinos eran mayoritariamente indígenas, gente de la tierra, mientras que los terratenientes eran casi totalmente descendientes de españoles, ingleses o italianos, es decir europeos, y quienes tenían algo de indígenas (los llamados "mestizos") escondían tal condición con un profundo desprecio, que teniendo un contenido de clase se expresaba en una suerte de diferenciación racial y étnica, que era entonces el factor principal de la contradicción, a nivel ideológico.

Siendo la contradicción principal la de los campesinos frente a los terratenientes y el aspecto principal de la contracción, a nivel ideológico, el de la raza-cultura, el problema, en aquel tiempo se planteaba como "el problema del indio", que era, en efecto, el principal problema de los terratenientes. En medio de estas condiciones aparecieron Tello, Valcárcel, Mariátegui, Haya, etc. y su obra, tanto en la praxis como en la teoría, condujo a resolver el aspecto principal de la contradicción y la contradicción principal.

Mariátegui planteó, que el tal "problema del indio" no era más que la expresión ideológica del problema real que era la de la tierra, dando origen, así, al Materialismo Histórico en el Perú. Valcárcel dijo que el "problema del indio" era un problema de carácter cultural, debido a la invasión europea y trató de explicar el problema en los términos que luego condujeron a la formación de la Etnología en el Perú. Otros teóricos explicaron el problema en términos sociológicos. Tello fue a las raíces, tratando de explicar al hombre andino, que ahora en condición de explotado era despectivamente calificado como "problema" en su propio país, dando origen a la Arqueología.

La Arqueología de Uhle y otros extranjeros tiene la virtud de estudiar al país como cuando se estudia cualquier objeto en un laboratorio, aparentemente sin más interés que el científico, pese a que siempre está encuadrado dentro de su propio condicionamiento social; la arqueología de Tello fue una aparte de la lucha de clases que se desarrollaba en el país, por lo tanto apasionada, vibrante, siempre a la ofensiva. Es la diferencia entre aquel que usa la ciencia como un arma para defender su propia vida y sus hermanos y aquel que la usa para solamente fabricar armas, la use quien las use; porque no podemos olvidar que la ciencia, especialmente la que estudia al hombre, siempre fue un arma de lucha social y si no que lo digan todos los historiadores y sociólogos del mundo.

Tello se encuentra en la "izquierda" de aquel tiempo, al lado de los oprimidos, al lado de sus padres y hermanos y frenético trata de mostrar que el despreciado "indígena" fue el creador de este mundo que ha hecho ricos a los europeos. Por eso pone toda su pasión para denunciar al mundo lo que su ciencia le revela: el mundo andino fue construido por el propio hombre andino; nadie trajo de afuera, nuestra civilización es autónoma. Se opone a Uhle violentamente, que creía ver en los Andes sólo un poco la tendencia del viejo mundo, de hacer derivar todo de su propio seno. Eso, la tesis de Uhle, favorecía la acción de los explotadores, también venidos de fuera; entonces, Tello, con Valcárcel, dijeron ino! y esgrimieron el autoctonismo y la unidad de la civilización andina como bandera. Se trataba de luchar contra los extranjeros y sus delegados peruanos y la arqueología fue buena arma, pese a que la técnica fuera insuficiente, por el hecho mismo de ser nueva, recién usada. 
Para plantear su esquema, Tello comenzó desde la tierra en su relación con el agua y así como la lluvias vienen de la selva hacia la tierra y convertidas en ríos bajan a la costa, él encontró que el hombre descubrió la agricultura en el selva, la elaboró y profundizó en la sierra y de allí la implantó hacia el litoral. Es curioso, pero parecería como que el odio de clases convirtió a Tello en un enemigo de la costa, casi totalmente poblada por extranjeros y todo lo que aparecía en la tierra de los Riva-Agüeros y otros hispanopensantes, resultada un reflejo tardío de lo que existía en la sierra. Eso explica su periodificación que habla de una primera edad "de los Andes Orientales", de una segunda "de los Andes Occidentales"; de una tercera "del litoral" y una última del "Tawantinsuyo”. Además, aún más, para Tello, el hombre andino hace el camino al revés que el de los invasores: ellos vienen por el mar de Occidente a Oriente; el hombre andino va de Oriente a Occidente. Alguien decía que Tello andaba contradiciendo siempre, que cuando entraba a las secciones de la Facultad de Letras preguntaba: “iDe qué se trata para oponerme?”. Pero eso sólo es cierto en boca de un hispanista, que miraba, naturalmente el mundo al revés que ellos, consecuentemente, debía estar siempre en la oposición y en ese tiempo en la Facultad de Letras había muy pocos que no miraban las cosas al revés, al revés de Tello.

Se nota que el esquema de Tello no es "cronológico", es decir, no refleja periodos. Esta es una de las principales dificultades para entenderlo; no sucedía esto con Uhle, quien planteaba un esquema sustancialmente cronológico, tanto como que ahora puede ser transcrito a las cronologías sin dificultad. Pero es que a Tello se le escapaba la cronología a un nivel secundario; su tarea consistía en explicarse cómo se produjo el dominio del hombre sobre la naturaleza, cómo se construyó la civilización. Al interior de su esquema existía el refuerzo cronológico, no siempre logrado con precisión, pero prevalecía la relación primaria entre la sociedad y el ambiente natural. Por eso las "civilizaciones de los Andes Orientales" primaban sobre las de los "occidentales" y éstas sobre las del "litoral", aún cuando él supiera que había coetaneidad entre ellos y aún cuando así lo dijera. Por eso, para explicar su esquema, recurrió a la imagen del árbol y sus ramas y la raíz "primordial” desconocida, más bien que a una simple secuencia cronológica. Los esquemas de Tello no revelaban periodos, revelaban procesos, un proceso que respondía a la encuesta social de la época de la que Tello era actor. Esa época que permitió que un partido político tomara como símbolo un ave de Chavín o que la carátula de los "7 ensayos" de Mariátegui se identificara con los oprimidos a través del nombre "Amauta". La época en que la izquierda toda se identificara con "el indio" aspecto principal de las contradicciones en la sociedad peruana de entonces.

El "indio" fue entonces reivindicado como forjador de toda la riqueza que usufructuaban los terratenientes y sus aliados extranjeros. En medio de la lucha social se dio, y, como parte de ella, la lucha ideológica. Tello fue una vanguardia de aquella lucha.

Nosotros creemos que sólo de este modo podemos entender su obra, pensar que Tello fue un arqueólogo frío, desposeído de carne y hueso, es pensar al revés. Sólo así podemos juzgar, también, lo que ocurrió en los veinticinco años posteriores a su muerte. Creer que un tal balance supone decir qué cosas no conoció Tello, no es recordar a Tello ni hacer un balance de su obra 25 años después, sino hacer una historia de lo que otros, en otras circunstancias históricas han hecho a favor de la ciencia. Por supuesto, son dos maneras opuestas de hacer el balance aunque se parta de las mismas referencias.

\section{TELLO, UNA DÉCADA DESPUÉS}

Veamos ahora qué pasó en la primera década inmediatamente posterior a la muerte de Tello. Fue una década de grandes cambios a nivel de la ciencia y también en la coyuntura social y económica del país.

A nivel de la ciencia, pocos años después de la muerte de Tello, salió a la luz, en 1951, el descubrimiento del radiocarbono (C14), que permitió, desde entonces, disponer de fechas absolutas para los restos arqueológicos, iniciando una era de gran preocupación por la ubicación cronológica de las culturas, a nivel por cierto 
menos especulativo que era en épocas anteriores. Gracias a los avances tecnológicos derivados de la investigación bélica consecuente de la II Guerra Mundial, se perfeccionó la fotografía aérea y se ampliaron notablemente las posibilidades prospectivas de los arqueólogos. La misma guerra "interesó" a los norteamericanos en una más íntima aproximación y conocimiento de América Latina, de modo que si bien el período bélico mismo, tuvimos a muchos arqueólogos del norte, con la post-guerra el interés arqueológico en los EE. UU. fue lo suficientemente grande como para armar un proyecto de gran magnitud como el que se hizo en el valle de Virú en 1946. Los resultados de aquel proyecto fueron especialmente beneficiosos a nivel metodológico, pues se ensayaron nuevos procedimientos de muestreo como el de James Ford o de estudio de patrones de doblamiento como el de Gordon Willey; aunque hechos deficientemente se iniciaron trabajos estratigráficos de gran extensión y, por primera vez, se fue en busca de periodos anteriores a la cerámica. Todo esto hecho por norteamericanos.

En el Perú, la sombra de Tello apenas permitió unas pocas aproximaciones de algunos de sus discípulos, algunos arqueólogos hicieron esfuerzos laterales, pero nadie pudo ampliar o modificar las hipótesis del sabio. Los norteamericanos dieron por muertas sus ideas y en aquella década, aparte del culto a Tello que se dio en el Museo Nacional de Antropología y Arqueología, no se avanzó más. La pregunta es ipor qué? Unos dicen que es porque Tello no dejó discípulos; mentira, porque sí los dejó; otros, porque nadie se interesaba, ipor qué?

Creemos que se explica esto si estudiamos detenidamente lo que ocurrió en la década del 50 en el Perú.

Este fue el periodo de la consolidación definitiva de nuestra dependencia económica de los EE UU que se realizó gracias a la dictadura militar encabezada por un señor de apellido Odría. En el curso de ella, la lucha social giró en torno a condiciones diferentes a las décadas precedentes dando origen a una total liquidación de cualquier movimiento que proclamase antagonismo con la clase dominante. El movimiento campesino aún no se recuperaba de sus bajas de la década del 30 y el movimiento obrero se había dispersado, liquidando, en la prác- tica, a su central clasista, la CGTP. Lo único que se mantenía coherente como vanguardia eran los partidos políticos de la pequeña burguesía y las capas medias urbanas, contra las cuales, en cierto modo, había surgido el golpe militar. La contradicción principal se mantenía al nivel de los campesinos y terratenientes, pero al mismo tiempo crecían las contradicciones en la ciudad, movilizando a las capas medias, las cuales comenzaron a agitar consignas populistas tales como "la defensa del petróleo" o "la reforma agraria". Ya no era un aspecto principal de contradicción el de la "cuestión indígena", sino que éste se trastocó en el "problema del subdesarrollo", por ende se comenzó a mirar en torno a la técnica y los profesionales técnicos comenzaron a crecer en importancia y poder; eso culminaría en el populismo del Dr. Belaúnde, un arquitecto, es decir un técnico, que prometía una solución al problema, la tecnología no tenía cabida en ningún lado y la "bandera" indigenista tampoco, que al revés de lo sucedido en la época de Tello, ahora era usada demagógicamente por los políticos, que aunque no tuvieron ni pizca de "indígenas" se proclamaban "orgullosamente" mestizos y hasta usaban símbolos indigenistas. De "problema del indio" pasó a "problema de desarrollo tecnológico" la cuestión del país.

De esto va a surgir, un poco más adelante, una arqueología al servicio del desarrollo económico, vía el Turismo, lo que conducirá a restaurar monumentos, promocionar ruinas, etc. pero Arqueología científica, no; no, pese a que hubieron meritorios esfuerzos individuales.

Por eso, esos diez primeros años, como dijéramos en 1957, cuando hablamos sobre Tello en este mismo lugar, sólo habían agregado, vía los trabajos de los norteamericanos y algunos otros arqueólogos de acción aislada, nuevos conocimientos sin modificar sustantivamente el marco teórico global que se debatía en vida del Dr. Tello. Los norteamericanos perfeccionaron la cronología formulada por Uhle y, obviamente, no se ocuparon más de Tello; en el Perú, nadie agregó nuevas hipótesis a las de Tello y todas las contribuciones adhirieron a las que iban en busca de una cronología. Aquí cabe la excepción de Rafael Larco Hoyle, que desde un lado opuesto a la de Tello, caminó por su propia senda. 
De los trabajos de Virú, surgió, sin embargo, un esquema que luego se generalizó por los Andes Centrales, y que en cierta manera es el que aún se usa en Arqueología; ese esquema, traducido por Julian Steward, a un lenguaje teórico global, se convirtió en el esquema de un proceso, reemplanzado con gran ventaja al esquema estrictamente cronológico que se estaba manejando desde Uhle y que alcanzó su máxima expresión en la síntesis que hizo Wendell Bennet en 1946 en el Handbook of South American Indians, de los periodos Tempranos, Medios y Tardíos y que el propio Bennet se vio precisado a modificar pocos años después, cuando publicó con Junius Bird su libro Historia de la Cultura Andina.

Pero había una diferencia sustantiva entre el proceso planteado a partir de Virú y el que Tello formuló. El principal factor de esta diferencia reside en que el primero se basa en el tiempo, con prescindencia de los cambios a nivel espacial y el segundo se basa en la relación espacio-hombre, con un secundario plano para el factor tiempo. Esto hace absolutamente disímiles los esquemas, de tal manera que no se puede siquiera pretender compararlos; sin embargo, como veremos, sólo de una suerte de solución de ambos se ha encontrado un camino de análisis más correcto.

\section{Tello, ENTRE 1957 y 1972}

Pasada la década de los cincuenta, se ingresó a una etapa de gran convulsión social en el llamado "Tercer Mundo" que entre otras cosas determinó la Revolución Cubana, los movimientos de liberación africanos, las guerrillas latinoamericanas y el ascenso, en el Perú, de nuevas contradicciones sociales. Nuevamente se levantó el movimiento campesino, esta vez ligado al movimiento obrero y de las capas medias urbanas, constituyéndose el imperialismo, claramente, como el aspecto principal de la contradicción y siendo la contradicción principal la existente entre la burguesía intermediaria del imperialismo y el pueblo explotado en su conjunto. El "problema del indio" dejó de constituir un problema para definirse como "problema de la tierra" e ideológicamente el problema se centró en el carácter que debía tener nuestro necesario proceso de cambio; mientras unos postulaban que el Perú debería ir al socialismo, otros sostenían que debía encontrarse una solución de desarrollo tecnológico simplemente.

Entonces, en medio de esto, se hace imprescindible volver sobre la historia, sobre el proceso peruano integral. Los que miran al Perú desde una mentalidad colonialista comienzan a analizar esta historia desde que llegaron los españoles y otros más escasos, desde la llamada emancipación, explicándose una historia de veinte mil años a base de lo que ocurrió en los últimos 150. Eso es como estudiar el corazón o las vísceras por el color de la piel, para diagnosticar un infarto o un cólico.

Entonces, volvemos a la Arqueología, pero, a una arqueología como la de Tello; aquí es donde importa el balance. La historia del Perú; como la historia de la mayor parte de los pueblos de Asia, África y América Latina, es una historia sin documentos que sólo puede ser entendida a partir de la Arqueología; la parte documentada de nuestra historia es sólo parte que nos corresponde como colonias del imperialismo; la parte no escrita es la que nos muestra la manera cómo el pueblo hizo su historia, resolviendo él, por sí mismo, su proceso.

Tello planteaba que el antiguo peruano fue creador de su propia historia, en íntima ligazón con el ambiente. No entramos en el detalle de su especulación teórica, pero es bien claro que él mantenía un cierto determinismo ambiental al interior de sus planteamientos, que se explica perfectamente en términos de su época y su lucha específica. Pero como todos lo destacan, el rol más importante de su teoría es le llamado "autoctonismo", es decir, la tesis que ubica al hombre como factor de su proceso. Él toma Chavín como punto de partida y desde entonces elabora la Civilización Andina, Más tarde, en estos últimos 25 años, se descubrió que antes de Chavín hubo una larga historia que luego ha permitido explicar Chavín mismo; se descubrió aquella oscura "era primordial" de la que hablara Tello. Lo importante es que eso no cambió en nada la tesis original de Tello y al contrario la consolidó, en el sentido que permitió mostrar que lo que hubo antes de Chavín fueron, en efecto, los anteceden- 
tes reales de aquello que Tello postulara sólo como hipótesis. Todavía quedan, por supuesto, muchas hipótesis por verificar y con seguridad los detalles en la hipótesis de Tello no se han confirmado y muchos no se confirmarán o se negarán, pero la línea general propuesta es hoy plenamente vigente y los arqueólogos actuales nos exigen una explicación del proceso, partiendo principalmente de las condiciones internas de desarrollo.

Parecería anacrónico un esquema de base espacial como el que Tello postulara, sin embargo, ahora, a diferencia de la década pasada, todos los arqueólogos parten de un análisis espacial combinado con el cronológico y cada vez más tiene sentido la tesis de Tello acerca del camino de Oriente a Occidente que él planteara, como es el caso de la tesis de John Murra sobre la "verticalidad" o la que sostiene Donald Lathrap a partir de sus investigaciones en la Selva.
Por eso, después de 25 años vuelve a cobrar importancia la arqueología a nivel científico, estrictamente ligada a la necesidad de explicar el proceso histórico. Esta vez no se trata de demostrar que el "indio" construyó su propia historia, pues ese eslabón fue cubierto por Tello con gran éxito; se trata de avanzar en el sentido de dar una explicación a las características, pasos y procedimientos involucrados. Un balance nos indica que se está avanzando en este sentido; un balance nos indica que sobre la obra de Tello se está activando una definición del proceso, dentro de nuevas condiciones de lucha social, que exigen y suponen un marco teórico diferente y nuevas soluciones.

Una arqueología así, social, fue iniciada por Tello; un balance de ella supone la necesidad de señalarse la tarea de seguir avanzando. 